\title{
Nutritional Status and Dietary Practices of Female Athletes
}

\author{
Sally Ezzat*
}

\begin{abstract}
The aim of this study was to assess the nutritional status and the feeding practices of female athletes practicing sport at the first class level. The sample of was taken from three sports clubs in Alexandria and included 124 athletes practicing handball, basketball or volleyball. Each athlete was privately interviewed using a pre-coded questionnaire to collect data on her educational level and her source of advice regarding athletic nutrition. Data was collected on the exact composition of the diet consumed before competition which were analyzed using the Egyptian food composition table. The diet was classified into balanced diet, unbalanced diet, high carbohydrate or high protein diets. Athletes were questioned about the time of consuming diet before competition and about fluid intake before, during and after the sport event. The athletes were also requested to provide information on the type of supplement frequently consumed. The nutritional status of the athletes was assessed using a set of anthropometric measurements including body weight, height, waist and hip circumferences. BMl was calculated. The results show that anthropometric measurements were within normal range. The team coach and older players were the main sources of nutrition advice. Only $22.6 \%$ of the athletes consumed a balanced diet and a similar proportion consumed a high carbohydrate diet. Meals were consumed by $42.8 \%$ of the players less than 3 hours before competition. Fluids were omitted by $33.1 \%$ and $50.8 \%$ of the athletes before and during competition. Nutritional supplements were taken by $73.4 \%$ of the players, performance enhancing supplement was most commonly used particularly by university graduates. The results confirm that poor dietary practices are quite prevalent and necessitate the inclusion of a nutritionist in the training team.
\end{abstract}

\section{INTRODUCTION}

The composition and timing of food intake of athletes can dramatically affect exercise performance, recovery rate, body weight and health. Sports nutrition has grown over the past two decades linking how an athletic eats with how they perform during practice and competition events. (1) Young athletes are either misinformed or have misconceptions about sports nutrition. Proper nutrition for young athletes is critical not only to promote performance, but more importantly to their growth, development and overall health. ${ }^{(2)}$

Female athletes are susceptible to

\footnotetext{
^Fellow of Nutrition Students' Hospital Alexandria University
} 
what is known as the female athlete triad of disordered eating, amenorrhea and osteoporosis. ${ }^{(3)}$ In addition, female athletes have excessive concern over body weight and resort to severe food restriction which may impair their nutrition. ${ }^{(4)}$ More importantly, female athletes stand a greater chance of developing complications or injuries associated with an increased level of exercise and poor dietary practices. ${ }^{(5)}$

Female athletes need to understand good nutritional practices. The limited information they learn in secondary school is slightly increased during college years. The kind of information learned and the importance young people place on this knowledge affect both their nutrition and performance. ${ }^{(6)}$

Ronsen et al (7) found that despite of differences between sports groups, many female athletes report unsatisfactory nutritional habits. Micronutrient supplementation was prevalent but varied between both groups of sports. Nichols et al (8) reported that $88 \%$ of female endurance athletes were consuming less than the minimum amount of energy needed for training. This may represent a chronic low level stressor instigating cortisol release. Such disorder occur more frequently in women with high level of cognitive and dietary restrain. ${ }^{(9)}$

When energy intake of female athletes is less than might be anticipated based on their training load, the intakes of iron calcium, vitamin $\mathrm{B}_{12}$ and Zinc and other nutrients are often below the recommended daily allowances. ${ }^{(10)}$ In addition, athletes involved in heavy training may need more of some vitamins such as thiamin, riboflavin and $\mathrm{B}_{6}$ because they are involved in energy production but the amount needed may be obtained by increasing food intake. ${ }^{(11)}$ However, if the athlete consume a low calorie diet with limited food intake, she will never cover her daily requirements from several nutrients 
such as minerals and vitamins.

Hydration status and fluid consumption have a profound effect on performance during endurance activities lasting more than 60 minutes. ${ }^{(12)}$ Water lost from the body via urine, gastrointestinal tract, evaporation from skin and respiration is exacerbated by heat, humidity or fluid restriction during exercise.(13) Those conditions are quite prevalent in Egyptian stadiums. It is very critical to pay special attention to fluid intake and hydration strategies of female athletes particularly during the hot weather which prevails over 6 months in Egypt.

Sound nutritional practices is essential to athletic success by maximizing performance and speeding recovery time. (14) However, female athletes have poor grasp of sound nutritional information which is mostly provided by trainers or coaches. ${ }^{(15)}$ Coaches can help to enhance the performance of their athletes by promoting good nutrition, however, they need to have the nutritional knowledge in order to encourage healthy food choices. ${ }^{(16)}$ Coaches of Egyptian teams are usually retired player without proper experience or training in physical education or nutrition. In fact, some trainers and coaches may recommended old food habits and taboos followed while they were practicing sports. This would be negatively reflected on the information they pass to their players who can not gain from recent development in sports nutrition.

Although the nutrition and feeding practices of athletes received considerable world wide attention and have been extensively used in upgrading the performance of athletes, this subject was not properly investigated in Egypt. Literature review revealed little information about the nutritional status of female athletes. Such activities in sports clubs are concentrated on the regulation of body weight of athletes. Therefore, this study was initiated to investigate the nutritional 
status and feeding practices of female athletes in Alexandria.

\section{Subjects and methods}

The subjects of this study were female athletes competing at the first class level. The study was implemented in three leading sports clubs in Alexandria Governorate. The administration of every club was met to obtain their permission to interview the athletes and to carry out the study. The aim of the study was explained to all athletes from teams in the three clubs and were invited to participate in the study. The total sample included 124 female athletes practicing either handball (42), basketball (36) or volleyball (46) .

Each player was privately interviewed using a pre-coded questionnaire to collect data on her level of education, the sources of information and advice concerning their nutrition. Athletes were requested to provide detailed information regarding their dietary practices including the composition of the diet consumed before competition and the timing of consuming such diet. The components of the diet were analyzed using the food composition table of Egyptian foods issued by the National Nutrition Institute(17). The diets were classified into balanced diet providing all nutrients in the recommended quantities, a diet rich in carbohydrates in which carbohydrates provide more than $75 \%$ of the calories, a diet rich in proteins in which proteins provide more than $20 \%$ of the calories and unbalanced diet deficient in one or more nutrients. The athletes were questioned about the exact quantities of water consumed before, during and after competition. They were also requested to provide information on the type of supplement frequently used while practicing sports. The supplements were either multivitamin preparation, minerals or performance enhancing supplement such as sports drinks, antioxidants, creatine or caffeine.

The nutritional status of the athletes 
was assessed by using a set of anthropometric measurements including body weight which was measured to the nearest $0.5 \mathrm{Kg}$, height recorded to the nearest $0.5 \mathrm{~cm}$. waist and hip circumferences recorded to the nearest 0.5 $\mathrm{cm}$. All measurements were made using standard techniques(18). Body weight and height were used in the calculation of the Body Mass Index (BMI; weight in kilograms divided by the square of height in meters).

Statistical analysis was performed using the statistical package for social sciences version 12.0. Descriptive data were calculated as frequencies. The association between variables was assessed using Chi-square test. Data on anthropometric measurements are presented in the form of means and standard deviation. Comparison between means was made using a one way analysis of variance. $P$ values less than 0.05 were considered statistically significant.

\section{RESULTS}

The mean anthropometric measurements of female athletes practicing different sports is presented in Table (1). The mean height of basketball players $(178.2 \mathrm{~cm})$ was statistically higher than that of volleyball or handball players, $173.1 \mathrm{~cm}$ and $171.6 \mathrm{~cm}$ respectively. On the contrary, handball players had the heaviest body weight $(66.1$ $\mathrm{kg}$ ) while basket ball players recorded the least body weight $(63.8 \mathrm{~kg})$. As a result, the body mass index of athletes from the latter group was least (20.1) and was significantly lower than that calculated for both volleyball and handball players, 21.4 and 22.6 respectively. Waist circumference was significantly lower $(63.8 \mathrm{~cm})$ for basketball players and was highest for athletes practicing handball $(72.8 \mathrm{~cm})$. Hip circumference was significantly higher $(93.8 \mathrm{~cm})$ for volleyball players, decreased to $91.6 \mathrm{~cm}$ for handball players and was least for basketball players. Analysis of variance revealed that anthropometric 
measurements varied significantly in not significantly affected by the source of athletes practicing different sports. information regarding athletic nutrition

The sources of advice about athletic (Table 3). The results show that $29.8 \%$ of nutrition for female athletes practicing the athletes consumed a high protein diet, different sports are illustrated in Table (2). The results show that coaches were the main source of nutrition advice (33.9\%) followed by older players (27.4\%) while physicians were the source for only $20.2 \%$ of the athletes. The source of nutrition information varied significantly with the level of education of the athletes $\left(x^{2}=\right.$ 14.05, $p<0.05)$. Older players were the main source of nutrition advice for students and athletes with secondary school education, $43.3 \%$, and $37.9 \%$ respectively. On the other hand, university graduates relied mostly on coaches (37.9\%) and physicians $(22.4 \%)$ to get the nutrition information. Mass media were the least important source of information for female athletes (18.5\%).

before competition, another 22.6\%

The nature of the diet consumed before competition by female athletes was between two and three hours before competition and the majority (33.0\%) 
consumed their diet more than four hours before competition. When the coach was the source of advice, $59.5 \%$ of the athletes had their diet more than four hours before competing . when older players and physicians gave the advice, the majority of the athletes had their diets three to four hours before competition, when mass media were the source of information, the majority of the players (34.8\%) had their diet less than two hours before competing. The differences were statistically significant $\left(x^{2}=24.05, p<0.001\right)$.

The mean fluid consumption by female athletes before, during and after competition is presented in Table 5. The mean fluid consumption was 0.85 liter before competition, decreased to 0.46 liter during competition and was highest (1.17 liter) after the sports events were completed. The data also show that while $50.8 \%$ of the athletes omitted fluid intake while competing, $33.1 \%$ did so during competition and only $16.9 \%$ did not take any fluids after competition. The results also show that $29.0 \%$ of the female athletes consumed less than one liter before competition, such percent increased to $35.5 \%$ while competing and declined to $21.8 \%$ when the sport event was completed. The majority of the players (47.6\%) consumed between 1-2 liters after competition and another $13.7 \%$ consumed more than 2 liters.

The results presented in Table 6 show that the level of education of the female athletes had a significant effect on the intake of nutritional supplement $\left(X^{2}=\right.$ 16.16, $p<0.05)$. The data show that $26.6 \%$ of the female athletes did not take any supplement, $23.4 \%$ used multivitamin preparations, $21.8 \%$ consumed mineral supplement and $28.2 \%$ used performance enhancer supplements. Students and athletes with secondary school education were more likely to consume mineral supplement $\quad(29.8 \% \quad$ and $\quad 24.1 \%$ respectively). Performance enhancer 
supplements were mostly consumed by evident between athletes practicing female athletes with university education different sports. Basketball player were $(41.4 \%)$, this was significantly higher than that reported among students and athletes taller and had a lighter body weight when compared with handball or volleyball with middle level of education $(16.2 \%$ and $17.2 \%$ respectively) players. (Table 1). It is evident that the nature of the sport requires the selection of

\section{Discussion} athletes with special body measurements.

Marinating a strong and healthy athletic performance is more than just a matter of training, practice and keeping in shape. The body of the athlete needs support in the form of sound nutrition, proper hydration and rest in order to keep performing and responding at peak level.

Female athletes tend to have nutritionally inadequate diet and thus may be at risk when taxing their bodies in heavy training schedule. Poor nutrition in female athletes is often associated with performance plateau and repeated injuries.

The results of this study show that Anthropometric measurements of female nutrition advice to female athletes, athletes were within normal range. however, older players who might have However, significant variations were inadequate knowledge had a strong 
influence on young female athletes. weight, select the diet that should be University educated athletes were more consumed before competition and to apply keen to follow physicians' advice while the recent concepts in athletic nutrition students were more responsive to their older team mates. Georgiou et al (19) reported that both athletes and coaches have limited nutritional knowledge and indicated that nutrition education is needed for those who influence young athletes.

More than 20 years ago, Barr reported that nutrition information sources were positively associated with nutritional knowledge of athletes. The most frequent sources were magazine, coaches and team mate, fewer athletes cited physicians as the source of advice.(20) This is quite comparable to that reported in the present study. The problem facing female athletes is that coaches and physicians do not have adequate knowledge about sports nutrition and may give the athletes wrong advice. It is essential to have a nutritionist in the training team to plan the meals for the athletes, follow the change in their body such as glycogen loading. This is not the case in almost all Egyptian teams competing at the national or international levels. The role of the nutritionist is usually assumed by the coach, the physician or some times older players. Clark et al (2003), expressed the importance a sport dietitian has in improving adequate nutrition education and improving performance during the competition seasons. ${ }^{(21)}$

The results presented in table 3 show that female athletes did not receive proper nutrition advice as $25 \%$ consumed unbalanced diet and $29.8 \%$ received a high protein diet. Active athletes often think they need to consume high protein diets to cover the building and repair of their tissue. A diet providing $15 \%$ of energy from protein would cover all the requirements and there is little need to recommend that athletes 
consume more protein. ${ }^{(22)}$

Despite of the importance of carbohydrates in the diet consumed before competition, only $22.6 \%$ of the female athletes consumed a high carbohydrate diet providing more than $75 \%$ of the calories. (Table 3) Athletes benefit the most from the amount of carbohydrates stored in the body. Carbohydrates yield more energy per unit oxygen consumed than fats. Because oxygen is the limiting factors in long duration events, it is beneficial to the athlete to use the energy source requiring the least amount of oxygen per kilocalorie produced. Consumption of carbohydrate fluids is also recommended to increase carbohydrate intake which is the primary fuel substrate during exercise and to help the players to remain in energy balance. ${ }^{(23)}$

Timing of food intake is very important for athletes. Eating sensibly before exercise assure that there is enough energy to fuel exercise and at the same time does not impose additional burden induced by the digestion and absorption of ingested food. It was surprising to note that $42.8 \%$ of the players consumed their meal less than 3 hours before competition, this would definitely have a negative effect on the level of athletic performance and indicate that such players did not receive proper nutrition advice not only on the type of diet they consume but also on the timing of such diet (Table 4).

Water is an important nutrient for the athlete. Athletes should start any event hydrated and replace as much lost fluid as possible by drinking chilled liquids at frequent intervals during the event. Chilled liquids are absorbed faster and help lower body temperature. In violation of all scientific recommendations, the results show that fluid was omitted by $33.1 \%$ of the players before competition, $50.8 \%$ during competition and another $16.9 \%$ did not drink any fluids at least for one hour after competition. Female athletes mentioned 
that after competition, their body female athletes take nutritional

temperature is high and water intake would harm them. This behavior indicates that, the athletes were poorly informed about their water and fluid requirements.

Fluid restriction will cause dehydration particularly in endurance events performed in hot environment as it always the case in Egypt. A hot environment can complicate the ability of the body to regulate temperature during exercise. ${ }^{(24)}$ It is extremely essential that appropriate quantities of fluids should be taken at regular intervals during exercise and proper hydration should be secured at the end of the sport event. ${ }^{(25)}$

Nutritional supplements are taken to meat the dietary needs of high performance athletes to enhance and improve exercise performance and training adaptation, prevention of nutritional deficiencies, increase muscle mass and improved recovery. ${ }^{(26)}$ The results presented in table 6 show that $73.4 \%$ of the supplement. Performance enhancing supplements such as sport drinks, caffeine, creatine and antioxidants were more popular and were consumed by University graduate at a high rate (41.4\%). Mineral supplements particularly iron may be needed for female athlete suffering from iron deficiency anemia. However, it was reported that mineral supplementation does not enhance performance in well nourished athletes. ${ }^{(27)}$

Multivitamin preparation was consumed by $21.8 \%$ of the athletes and was more common among university graduates $(29.3 \%)$. Some athletes may be at risk of vitamin deficiency such as those who do not eat a well balanced diet, or those following a calorie restricted diet. Such athletes should take a multivitamin preparations. However, Increased caloric intake through a varied diet ensures a sufficient amount of vitamins and minerals. There is no evidence that taking more 
vitamins than is obtained by eating a variety of foods will improve performance.

Table 1: Mean anthropometric measurements of female athletes practicing different sports

\begin{tabular}{|c|c|c|c|c|}
\hline \multirow[b]{2}{*}{$\begin{array}{l}\text { Anthropometric } \\
\text { measurements }\end{array}$} & \multicolumn{3}{|c|}{ Number examined } & \multirow[b]{2}{*}{$\begin{array}{l}\text { ANOVA } \\
\text { (F) }\end{array}$} \\
\hline & $\begin{array}{l}\text { Handball } \\
\text { (42) }\end{array}$ & $\begin{array}{l}\text { Basketball } \\
\text { (36) }\end{array}$ & $\begin{array}{l}\text { Volleyball } \\
\qquad(46)\end{array}$ & \\
\hline Height $(\mathrm{cm})$ & $171.6 \pm 4.3$ & $178.2 \pm 7.3$ & $173.1 \pm 8.1$ & $69.41^{*}$ \\
\hline Body weight $(\mathrm{kg})$ & $66.1 \pm 5.9$ & $63.8 \pm 5.7$ & $64.6 \pm 5.4$ & $9.56^{*}$ \\
\hline Body mass index $(\mathrm{kg} / \mathrm{m} 2)$ & $22.6 \pm 1.99$ & $20.1 \pm 2.4$ & $21.4 \pm 2.2$ & $27.42^{*}$ \\
\hline Waist circumference $(\mathrm{cm})$ & $72.8 \pm 5.8$ & $63.8 \pm 7.0$ & $69.6 \pm 6.3$ & $126.04^{*}$ \\
\hline Hip circumference (cm) & $91.6 \pm 5.2$ & $88.2 \pm 6.3$ & $93.8 \pm 5.9$ & $54.96^{*}$ \\
\hline
\end{tabular}

Difference significant at $p<0.001$

Table 2: Sources of advice about athletic nutrition for female athletes from different educational levels

\begin{tabular}{|c|c|c|c|c|c|c|c|c|}
\hline \multirow{3}{*}{$\begin{array}{l}\text { Source of } \\
\text { advice }\end{array}$} & \multicolumn{6}{|c|}{ Educational level } & \multirow{2}{*}{\multicolumn{2}{|c|}{ Total }} \\
\hline & \multicolumn{2}{|c|}{ Students } & \multicolumn{2}{|c|}{ Middle } & \multicolumn{2}{|c|}{ University } & & \\
\hline & No. & $\%$ & No. & $\%$ & No. & $\%$ & No. & $\%$ \\
\hline Coaches & 11 & 29.7 & 9 & 31.0 & 22 & 37.9 & 42 & 33.9 \\
\hline Older players & 16 & 43.3 & 11 & 37.9 & 7 & 12.1 & 34 & 27.4 \\
\hline Mass media & 5 & 13.5 & 5 & 17.3 & 13 & 22.4 & 23 & 18.5 \\
\hline Physicians & 5 & 13.5 & 4 & 13.8 & 16 & 27.6 & 25 & 20.2 \\
\hline Total & 37 & 100 & 29 & 100 & 58 & 100 & 124 & 100 \\
\hline
\end{tabular}

$X^{2}=14.05, p<0.001$ 
Table 3: Effect of the source of nutrition advice on the nature of diet consumed before competition

\begin{tabular}{|c|c|c|c|c|c|c|c|c|c|c|}
\hline \multirow{3}{*}{ Nature of diet } & \multicolumn{8}{|c|}{ Source of nutritional advice } & \multirow{2}{*}{\multicolumn{2}{|c|}{ Total }} \\
\hline & \multicolumn{2}{|c|}{ Coaches } & \multicolumn{2}{|c|}{$\begin{array}{l}\text { Older } \\
\text { players }\end{array}$} & \multicolumn{2}{|c|}{$\begin{array}{l}\text { Mass } \\
\text { media }\end{array}$} & \multicolumn{2}{|c|}{ Physicians } & & \\
\hline & No. & $\%$ & No. & $\%$ & No. & $\%$ & No. & $\%$ & No. & $\%$ \\
\hline Balanced & 7 & 16.7 & 8 & 23.5 & 5 & 21.7 & 8 & 32.0 & 28 & 22.6 \\
\hline High carbohydrate & 11 & 26.2 & 8 & 23.5 & 4 & 17.4 & 5 & 20.0 & 28 & 22.6 \\
\hline High protein & 14 & 33.3 & 11 & 32.4 & 5 & 21.7 & 7 & 28.0 & 37 & 29.8 \\
\hline Unbalanced & 10 & 23.8 & 7 & 20.6 & 9 & 39.1 & 5 & 20.0 & 31 & 25.0 \\
\hline Total & 42 & 100 & 34 & 100 & 23 & 100 & 25 & 100 & 124 & 100 \\
\hline
\end{tabular}

$X^{2}=5.41$, difference not significant.

Table 4: Impact of source of nutrition advice on the timing of diet consumption before competition

\begin{tabular}{|c|c|c|c|c|c|c|c|c|c|c|}
\hline \multirow{3}{*}{$\begin{array}{l}\text { Time of diet } \\
\text { consumption } \\
\text { before } \\
\text { competition } \\
\text { (hours) }\end{array}$} & \multicolumn{8}{|c|}{ Source of nutritional advice } & \multirow{2}{*}{\multicolumn{2}{|c|}{ Total }} \\
\hline & \multicolumn{2}{|c|}{ Coaches } & \multicolumn{2}{|c|}{$\begin{array}{c}\text { Older } \\
\text { players }\end{array}$} & \multicolumn{2}{|c|}{$\begin{array}{l}\text { Mass } \\
\text { media }\end{array}$} & \multicolumn{2}{|c|}{ Physicians } & & \\
\hline & No. & $\%$ & No. & $\%$ & No. & $\%$ & No. & $\%$ & No. & $\%$ \\
\hline$<2$ & 5 & 11.9 & 6 & 17.7 & 8 & 34.8 & 6 & 24.0 & 25 & 20.2 \\
\hline $2-$ & 6 & 14.3 & 8 & 23.5 & 7 & 30.4 & 7 & 28.0 & 28 & 22.6 \\
\hline 3- & 6 & 14.3 & 11 & 32.5 & 5 & 21.8 & 8 & 32.0 & 30 & 24.2 \\
\hline$>4$ & 25 & 59.5 & 9 & 26.5 & 3 & 13.0 & 4 & 16.0 & 41 & 33.0 \\
\hline Total & 42 & 100 & 34 & 100 & 23 & 100 & 25 & 100 & 124 & 100 \\
\hline
\end{tabular}

$X^{2}=24.05, p<0.001$ 
Table 5: Fluid consumption by females athletes before, during and after competition.

\begin{tabular}{|c|c|c|c|c|c|c|}
\hline \multirow{2}{*}{$\begin{array}{c}\text { Fluid consumption } \\
\text { (liters) }\end{array}$} & \multicolumn{6}{|c|}{ Timing of consumption } \\
\cline { 2 - 7 } & \multicolumn{2}{|c|}{ Before } & \multicolumn{2}{c|}{ During } & \multicolumn{2}{c|}{ After } \\
\cline { 2 - 7 } & No. & $\%$ & No. & $\%$ & No. & $\%$ \\
\hline Omitted & 41 & 33.1 & 63 & 50.8 & 21 & 16.9 \\
\hline$<1$ & 36 & 29.0 & 44 & 35.5 & 27 & 21.8 \\
\hline $1-$ & 32 & 25.8 & 8 & 6.5 & 59 & 47.6 \\
\hline $2+$ & 15 & 12.1 & 9 & 7.2 & 17 & 13.7 \\
\hline Total & 124 & 100 & 124 & 100 & 124 & 100 \\
\hline $\mathrm{x} \pm$ S.D & $0.85 \pm 0.8$ & $0.46 \pm 0.7$ & $1.17 \pm 0.8$ \\
\hline
\end{tabular}

Table 6: Nutritional supplements frequently consumed by female athletes from different educational levels

\begin{tabular}{|c|c|c|c|c|c|c|c|c||}
\hline \multirow{2}{*}{$\begin{array}{c}\text { Type of } \\
\text { supplement }\end{array}$} & \multicolumn{6}{|c||}{ Educational level } & \multicolumn{3}{c|}{ Total } \\
\cline { 2 - 10 } & Students & \multicolumn{2}{|c||}{ Middle } & \multicolumn{2}{c||}{ University } & \\
\cline { 2 - 10 } & No. & $\%$ & No. & $\%$ & No. & $\%$ & No. & $\%$ \\
\hline None & 13 & 35.1 & 12 & 41.4 & 8 & 13.8 & 33 & 26.6 \\
\hline Multivitamins & 7 & 18.9 & 5 & 17.3 & 17 & 29.3 & 29 & 23.4 \\
\hline Mineral & 11 & 29.8 & 7 & 24.1 & 9 & 15.5 & 27 & 21.8 \\
\hline Performance enhancers & 6 & 16.2 & 5 & 17.2 & 24 & 41.4 & 35 & 28.2 \\
\hline Total & $\mathbf{3 7}$ & $\mathbf{1 0 0}$ & $\mathbf{2 9}$ & $\mathbf{1 0 0}$ & $\mathbf{5 8}$ & $\mathbf{1 0 0}$ & $\mathbf{1 2 4}$ & $\mathbf{1 0 0}$ \\
\hline
\end{tabular}

$X^{2}=16.6, p<0.05$ 


\section{REFERENCES}

1. Clark, K. Sports nutrition counseling documentation of performance. Clinical Nutrition. 1999; 14 (2): 34-39.

2. Cotugno RD, Vickery CE, McBee S. Sports nutrition for young athletes. Journal of School Nursing 2005; 6: 323-328.

3. Joy E, Clark N, Ireland ML. Team management of the female athlete triad, part I: What to look for, What to do. Sports Med. 1997; 25(3): 95-110.

4. Ziegler P, Hensley S, Roepke JB. Eating attitude and energy intake of female skaters. Med Sci Sports 1988; 30: 583-586.

5. Bass M, Turner L, Hunt S. Counseling female athlete: application of the stages of change model to avoid disordered training, amenorrhea and osteoporosis. Physiological Reports. 2001; 88: 1153-1160.

6. Wiita B, Stombough I, Buch J. Nutrition knowledge and eating practices of young female athletes. $J$ Physical Education and Recreation 1995; 66: 1-3.

7. Rosnen O, Borgen JS, Maehlum S. Supplement use and nutritional habits in Norwegian elite athletes. Journal of Medicine and Science in Sports 2007; 9(1): 28-35.

8. Nichols PE, Jonnalagadda SS, Rosenbloom CA, Trinkaus $M$. Knowledge, attitude and behaviours regarding hydration of colligate athletes. Int J Sport Nutr Exer Metab 2005; 15: 515-527.

9. Mclean JA, Barr S, Cognitive dietary restraints is associated with eating behaviours, lifestyle practices, personality characteristics and menstrual irregularity in college women. Appetite 2003; 40: 185-192.

10. Hawley JA, Dennis SC, Lindsay F.H. Noakes TD. Nutritional practices of athletes: Are they Sub- Optimal. J. Sport Sci. 1995, 13(51): 575-5-81.

11. Manore M. Vitamins and Minerals: Part II who needs to supplement? ACSM'S Health and Fitness. Journal 2001; 5(4): 30-34.

12. American College of sports Medicine. Position stand: Exercise and fluid replacement. Medicine and Science in Sports and Exercise, 1996; 28: 1-7.

13. Barr SL. Effects of hydration on exercise performance. Cand. J. of Applied Physical. 1999; 24(2): 164172.

14. Hargreaves M. Carbohydrates and lipid requirements in soccer. Journal of Sports Science. 1994; 12: 13-16.

15. Burns RD, Schiller R, Merrick MA, Wolf $\mathrm{KN}$. Inter collegiate student athlete use of nutritional supplement and the role of athletic trainer and dietitians in nutrition counseling. Journal of the Amer Dietit. Assoc 2004; 104: 246-249.

16. Corely G, Demarest-litchford M, Bazzarre T. Nutrition knowledge and dietary practices of college coaches $\mathrm{J}$. Amer Dietit. Assoc. 1990; 90: 705709.

17. Food composition tables for Egypt. $1^{\text {st }}$ ed. Cairo: Nutrition Institute; 1996.

18. Jelliffe EF, Zerfas A, Neumann CG. Community, nutritional assessment. Oxford University press; 1989.

19. Georgiou C, Betts N, Hoot, Glenn M. young adult exercisers and non exercisers differ in food attitude and food choices. Int J Sport Nut. 1996; 6: 402-413.

20. Barr SI Nutrition Knowledge, attitude and dietary practices of female recreational athletes. J Nutr Edu. 1986; 18: 167-172.

21. Clark M, Reed DB, Crouse SF, Armstrong RB. Pre-and post-season dietary intake, body composition and performance indices of NCAA Division I female soccer players. Journal of 
Sport Nutrition and Exercise Metabolism 2002; 13: 303-319.

22. Lemon PWR. Beyond the zone: Protein need of active individuals. J Am Coll Nutri. 2000; 8: 426-447.

23. Martin L, Lambeth A, Scott D. Nutritional practices of national female soccer players: Analysis and Recommendations. Journal of Sports Science and Medicine 2006; 5: 130137.

24. Schnirring L. New hydration recommendation risk of hyponatremia plays a big role. Physician and Sports Med. 2003; 31(7): 15-22.

25. Schirreffs SM, Armstrong LE, Cheuvront SN. Fluid and electrolyte needs for preparation and recovery from training and competition. J Sports Sci. in 2004; 22: 57-63.

26. Erdman $\mathrm{K}$, Fung $\mathrm{T}$, peimer $\mathrm{R}$. Influence of performance level on dietary supplement in elite Canadian athletes. Medicine and Science in Sports and Exercise. 2006; 38(2): 349-356.

27. Williams $\mathrm{MH}$. Dietary supplements and sports performance: Minerals. Journal of the International Society of Sports Nutrition. 2005; 2: 43-49.

28. Williams M. Dietary supplements and sports performance. Introduction and Vitamins. Journal of the International Society of Sports Nutrition 2004; 1: 4-6. 